\title{
Measuring Innovation Capability - Assessing Collaborative Performance in Product-Service System Innovation
}

\author{
Johanna Wallin ${ }^{12}$, Andreas Larsson ${ }^{3}$, Ola Isaksson ${ }^{12}$, Tobias Larsson ${ }^{1}$ \\ ${ }^{1}$ Luleå University of Technology, Luleå, Sweden \\ ${ }^{2}$ Volvo Aero Corporation, Trollhättan, Sweden \\ ${ }^{3}$ Lund University, Lund, Sweden
}

\begin{abstract}
This paper reports on a qualitative study, carried out at a Swedish aero engine manufacturer. The study was initiated to explore key indicators related to innovation capability in a Product-Service System (PSS) context. Developing PSS changes the dynamics of collaboration, since the offering of such systems usually involves a network of partners sharing the responsibility for a delivered function over a full lifecycle. In particular, this paper focuses on describing aspects related to external and internal collaboration, and it further discusses how to measure the company's collaborative performance, taking into account both activity and effect measures.
\end{abstract}

\section{Keywords:}

Innovation Capability, Performance Measurement, Collaboration, Product Service Systems

\section{INTRODUCTION}

Innovation capability, broadly defined as the ability to routinely achieve innovative outcomes, is crucial for industrial companies today in order to be competitive on the market over time. They need to trust their capability to innovate again and again, and by deploying appropriate metrics of innovation capability, they could (1) establish the current baseline when it comes to innovation capability, (2) establish useful indicators related to potential future outcomes, and (3) establish intervention mechanisms to increase the innovation capability when and where needed.

Manufacturing industries are undergoing a transition towards integrating more services into the traditional product concepts. On the one hand, this creates new opportunities for the companies. On the other hand, vanishing boarders between services and hardware changes the way companies plan, develop and produce such Product-Service Systems (PSS) [1]. Innovations where services are a key ingredient of the solution typically require skills and competencies that may not reside fully within a manufacturingfocused organization.

To achieve innovation in the comprehensive PSS domain, companies need to reassess how they collaborate both internally and externally, considering the roles, responsibilities, competencies and skills of an increasingly diverse and distributed set of stakeholders. Key questions when assessing the innovation capability within the context of collaboration are, first, how effective are current collaborative practices? Second, how can these collaborative practices be improved? Answering these two questions introduces a third one - how can the collaboration capability be measured? These were the guiding questions behind this research project being conducted at a Swedish engine component manufacturer in the aerospace industry, and part of a large group in the transport business. The company has a history of technology development, product development, manufacturing and in-service support, but has recently positioned itself as a provider of solutions, including products, technologies and services. Such a move implies that the companies need to improve their capability to develop and offer product-service system solutions [1].
On a product development level, innovation capabilities are relatively well known for hardware issues, but service integration implies development of new business models, new competences and collaborative partnerships - both internally and externally. Careful strategic leadership is needed since this is a transition challenging tradition and mindset. To reach the desired future state of a high innovation capability and successful development of product-service systems, several steps need to be taken. One of these steps relates to measuring the innovation capability, and establishing metrics with regard to external and internal collaboration is the topic of this paper. Developing and offering PSS solutions require close business collaboration with other companies and organizations throughout the lifecycle and along the valuechain of the solution. The changing conditions related to offering solutions rather than products require a better understanding of the company innovation capability.

Previous work [2] at the company has identified six areas of importance when measuring innovation capability at the company: Project selection, Customer involvement, Interaction between functions, Innovation methodology, Team climate and Innovation rewards. Furthermore, it was found that dividing the metrics into 'Activity' and 'Effect' enabled the organization to deepen the understanding of both real-time performance indicators, which can give a more or less 'instant' feedback to ongoing activities, and the after-the-fact performance measures, allowing a more careful analysis of how particular activities relate to particular outcomes.

Two of the identified areas were found to be of particular importance when developing PSS as opposed to developing 'only' products or technologies. These areas are Customer involvement and Interaction between functions, where both describe collaboration and networking, the first focused on external collaboration, and the second focused on internal collaboration. A PSS commitment requires an exceptionally close contact with the customer throughout the whole lifecycle, and it also increases the demands on close collaboration between product development functions and service development function. 


\section{MEASURING INNOVATION}

According to Olsson et al [3], how you define innovation affects the ways to measure it. An innovation is often described in literature as something more than a great idea, since ideas essentially need to be realized and add value for both customers and firms to be an innovation [3][4]. Schramm [4] signifies the importance of measuring both input and output to innovation. Andrew et al [5] include, apart from input and output, processes (which act on and transform the inputs). Chiesa et al [6] note that focusing on input and output indicates rather than explains performance and in order to understand the innovation performance one must include investigate innovation capability and the processes involved in developing and exploiting innovations. Cordero [7] summarizes measures of innovation performance in firms and highlights that performance evaluation in many organizations focuses mainly on resources and outputs, such as R\&D expenditure, speed to market, market share, and the number of new products, thus tending to ignore the processes in-between.

Thus, there is a fundamental problem with focusing on, for example, financial metrics since past performance is often a poor indicator of future success. A successful business does not necessarily imply that a company has a high innovation capability. Poor innovation practices can lead to good outcomes and good innovation practices can lead to poor outcomes. Rosenzweig [8] notes, for instance, that just because "...a given choice didn't turn out well doesn't mean it had been a mistake. It is therefore necessary to examine the decision process itself and not just the outcome." Muller et al [9] also use the same three categories: input, output and processes, and further suggests that metrics are tailored in three views Capability, Resources and Leadership. Olsson et al [3] highlight the importance and need of every organization to figure out what is important to measure in view of their specific circumstances. Werner et al [10] discuss the use of objective/subjective as well as quantitative/qualitative metrics and claim that a combination of multiple methods would reduce biases, take advantage of multiple dimensions of excellence and provide built-in checks and balances to capture the full range of the R\&D process. It is frequently stated that metrics can lead organizations to successfully capitalize on innovations [4][11] and it can also be seen as a way for companies to better understand if it is worth pursuing potential high-risk projects. Measuring innovative capability is important from a change management perspective and is crucial to the successful identification and selection of high impact ideas for product development.

\section{DATA COLLECTION}

This paper reports on an ongoing study of the company's current state-of-practice in terms of performance measurements for innovation capability in general and for product-service systems in particular. Five project managers, responsible for advanced product and technology development projects at the early stages of the innovation process were interviewed together with five other individuals involved in service, business development and/or technology development. The rationale for selecting these individuals is that they are organizationally distributed across the company so that they could serve as, and provide, representative examples of the established culture and work methods, and thus provide insight into what factors they believe affect the innovation capability in product-service system innovation at the company, and take part in a discussion around how this capability could be more effectively measured and improved.

The methodology used to capture empirical data focuses on semiformal interviews, one with each of the selected individuals which also included open discussion on the topics, and close observations of meetings regarding the development of product-service system solutions. The findings from interviews and observations are discussed in reference to the findings from the literature review.

\section{PRODUCT-SERVICE SYSTEM DEVELOPMENT IN AEROSPACE}

It is a pre-requisite to develop a deep understanding of the contextual situation in order to establish relevant metrics [6]. The aerospace industry is characterized by high technical complexity, high development cost, long product lifecycles, and increasing service integration in offers such as TotalCare $₫$ by Rolls-Royce, [12] where airlines pay for service in a package with the product. Since the product development is mainly contract driven, binding contracts are normally signed before development work starts and risks are shared.

Many industries are focusing on traditional lifecycle services (e.g. supply of spare parts, repairs and maintenance) to generate higher profits [13], and extending the PSS components in such business models can offer significant growth potential. Service offers provide an opportunity to differentiate against competitors, build customer loyalty, distribute the revenue profile during the lifecycle and increase the demand for the core product. Integrating services and physical products into a single 'package' comes with a more complex character of the offer. Managing such complexity may cause an extra burden on the information systems required to support the sales and maintenance of such 'packages'. Since addressing these challenges might not be the core expertise of the company [14], important questions relate to whether the company should look towards external partners to realize the idea on the market, or start growing the knowledge internally.

The company's history of technology development and manufacturing has given it a strong product focus even though service and maintenance also have been important parts of the business for a long time. The customer for commercial product development projects is the Original Equipment Manufacturer (OEM) of the engine (i.e. General Electric, Rolls-Royce, Pratt \& Whitney), whereas the company is the OEM of the engine on the military market, with the Swedish Air Force as the customer. Recently the company has positioned itself as a provider of solutions and the increase in solution offers requires ownership of the product/technology for the full lifecycle of the solution. Such solutions require a close collaboration with customers, and could be described as a risk and reward sharing partnership rather than as a customer-supplier relationship. The company offers an extensive range of services, including sales of spare parts for aircraft engines and aircraft, as well as maintenance, repair and overhaul of aircraft engines and gas turbines. The military business side has come far in integrating services into the product offers and it is a sector where there already exist complete product-service system offers. Most of the service development is also on the military side, the cradle of the core business, which makes service development in this area easier. However, on the commercial market where aircraft engines components are developed in partnership with the OEM, the services provided have been separate from the total product offers.

Product-service system development also requires a close interaction between the different functions and departments within the company, since product development and service development involve different parts of the organization. Further, it can also involve collaboration outside company borders, such as cooperation within the group or other collaboration partners. 
The company uses the term Soft Products to describe products and services that enhance the customer experience and satisfaction beyond the core product, and the biggest Soft Product is for some considered to be their product development organization, since the customer, the OEM of the engine, not only gets a hardware product but a partner who develops it, puts it in production and then supports it. Also, the technology development is for some considered to be a form of service, since it adds value to the customer and on the space market the company sometimes works as a consultant. Consultancy could also be performed in other business areas, although the organization is not built for these kinds of services, given that the company is used to large, multi-year projects rather than a certain amount of consultancy hours. The Soft Product strategy designed by the company mandates that the 'soft' products or services that are developed should be connected to the core business of the company. Things that are not included in the core business should be outsourced to other companies within the group or to external companies. However, it is rare that the company collaborates with another group company and the main reasons for this, according to informants, is that the aerospace industry is unlike other transport businesses within the group, and that other group companies are more truck-oriented, and not used to the airworthiness requirements of the aerospace industry. However, when it comes to product-service systems, other group companies have great experience, knowledge and resources regarding diagnostics, handling large amounts of computer data, making service interfaces and customizations, which are important for service development. On this issue the company has taken a collaborative leap, and for the first time several companies within the group are working together to develop a product-service system for military aircrafts.

\section{CUSTOMER INVOLVEMENT - EXTERNAL COLLABORATION}

Literature often points to the importance of customer involvement in the product development process in order to fully understand the needs and expectations of the customer [3][15]. Cao et al [16, p.364] identified five dimensions that make up supply chain collaborative advantages: process efficiency, offering flexibility, business synergy, quality and innovation. Cao notes: "The definition and measures of collaborative advantages can help managers to define specific actions to be taken collaboratively to improve shared supply chain processes that benefit all members". Eppinger et al $[17$, p.22] states: "Best practice in product development (PD) is now rapidly migrating from local, cross-functional collaboration to a mode of global collaboration".

On the commercial market, the company has specialized in certain components of the aircraft engine and their customers/partners have specialized in others. Dealing with the interfaces between the different components put increasing demands on collaboration, but the roles of customers or suppliers are blurry. The customer can be described as "part of the team" or, as one of the informants put it: "If we are wrong, they are wrong, if we are right, they are right. We are not always right, sometimes we fail together". Several departments communicate directly with the customer and this communication is not only on a management level, team members communicate directly with the customer and this is important for the collaboration. The partnership also means that the customer has higher requirements on the way of working than the average customer of a consumer product would have. Since the way of working directly affects the trustworthiness within the partnership and this is especially important the more radical the project is. Certain critical areas, such as engine mounts and acoustics, also involve collaboration with the aircraft manufacturer.
Product development always has an apparent external customer but this is not always the case for technology development. The external customer creates a stronger driving force for expected results, but it can also create boundaries for the innovation capability. Technology development teams that only have an internal customer can develop in the direction that is most profitable for the company alone. The external customers are considered to be more pushing and active than the internal customers. This points out the importance of keeping both internal and external customers close. The customer involvement is as important, if not more important, when developing product-service systems. However, when providing services the company does not only have to look to their usual customers, but also to the customers of the customer, e.g. the airlines. Here, it is also important to note that this essentially means that they may become competitors with their customers/partners, which provide similar services. The key is to provide services that are close to their own core business but in the periphery of their customers' business. If services and maintenance are to be provided on an engine, a contract is needed with the OEM of the engine.

One informant described the importance of infusing confidence to the customer by coming up with ideas, being proactive, showing the customer their way of working and developing their methods. The company needs good ideas in order to 'push' the customer. This points to the importance of a methodology and a process, which makes the most out of the relationship between the team and the customer, making it as profitable as possible for both company and customer. There is much to gain by going outside the company borders for collaboration. This is how one project manager described it: "As long as we are just small teams, we cannot afford to be more than six, seven people in the small projects; we are so smoked, if we cannot use the outside world. Usually other people have great ideas, better knowledge, we know our application, but we need to go out and find those other pieces that are needed. /.../ As long as we just sit in our small teams internally, sure we can come up with the world's best solution but the probability is quite low. If we constantly work with the world around us the likelihood is much greater". This points to the importance of not only collaborating externally with customers but also with suppliers and university researchers.

\section{INTERACTION BETWEEN FUNCTIONS - INTERNAL COLLABORATION}

The importance of collaboration in product development and innovation is often stated in literature [18][19][20]. For instance, Björklund [19] identifies collaboration as one of the key factors when improving project performance. Sosa et al [21] point out the importance of functions involved talking to each other to anticipate the unexpected problems to save time and cost. The company organization consists of different business functions, such as marketing, purchasing, production and product development, and each business function consists of several departments. The development teams consist of people from different departments and different parts of the organizations and this collaboration is essential for all projects.

There are differences in opinion whether or not the collaboration and communication at the company is satisfactory. The informants who considered the communication to be satisfactory also described the company as 'small'. There are advantages with this, according to one informant: "I think it works. We are such a small company. The advantage is that things go pretty fast and it's quite informal. The ceiling is quite high when it comes to bouncing ideas." 
The collaboration within one business function is always described as easier than the collaboration between them. The informants who considered the communication to be unsatisfactory usually had a hard time describing why this is the case. Several of them described the importance of having a common interest when collaborating with other departments even though there often were disagreements on what was important. The collaboration between departments and functions involves many compromises and if many people are involved it can slow down the pace because of the large amount of input, but this collaboration is still described as very important since ideas appear from many sources. Although the projects consist of people from different functions, the focus is on developing products (even in technology development projects). Services are not taken into consideration, except possibly reparations of the product. The reason for this, according to one informant, is considered to be the educational background of the employees: "We are mechanical and electrical engineers all of us. It is that simple."

One important collaboration activity for the development projects are the gate reviews; this is where many important decisions are made. The product and technology development processes are stage-gate processes with decision gates to pass through based on thorough reviews of the project status. Each gate has its checklist and control questions, but these are normally very product focused, and no checklist items in any gates involve services, or poses questions such as: is it possible to refine this product to include a service? Opportunities for service development can be lost when there is no demand in exploring them. If a project is not fulfilling the gate criteria, it is not allowed to pass through the gate. However, when the project has a deadline towards a customer and risk receiving late fees if not delivered, it is sometimes not feasible to make the decision to stop the project at the gate. These gate reviews in early stages are arranged by the engineering organisation and the focus is on technical performance rather than, for instance, the ease of manufacturing. One project manager thought that the collaboration and the handover of projects would perhaps be easier if the responsibilities at these gates would alternate between persons from different functions. Further, if the person responsible for manufacturing aspects would have a stronger vote, the project might not pass through the gate so easily.

Lack of time within the teams can hinder innovation and collaboration. Sharing a good idea can sometimes backfire on the person who created the idea, in the form of an expectation to also follow-through with the implementation of the idea. This can hinder a person from sharing an idea unless this person has time to develop it him/herself. This points to the importance of collaborating within the team when ideas erupt, implying that ideas should not necessarily be owned by the individual but by the whole team, which is also collectively responsible for its development.

There are various tools for external communication and collaboration, such as Microsoft Office Live Meeting and conference calls, which are widely used within the company. Also, video conference software and equipment is available, but is not so commonly used. Internally within the group there are also commonly used online tools, such as chat, intranet and blogs. Internal blogs are often used by the development projects to let the rest of the company know the status of the projects. It is one way for the project teams to communicate to the rest of the company However, these blogs can be hard to get started: "There is a resistance to writing; you don't see the point in it. On the other hand you see the point in it when others are writing so I can read it". One project manager expressed the need to improve this way of communicating and suggested an internal version of Facebook as a way for individual employees to report status updates: "It is the little things that doesn't mean anything by themselves but together gives the whole picture. I.../If we had Facebook here and I would know what everyone in [PROJECT X] were doing, it would lead to discussions and in the end I would understand what's going on in the project and perhaps I would know when I could help or we could help or they could help us". This highlights the importance of not only having tools for direct communication between people, but also deploying tools that allow people to communicate indirectly, for instance by overhearing communication between other individuals and groups, and observing traces of information left by other people. In these days of online social networking, many people are used to this way of communicating and screening information.

Job rotation is another important aspect related to the collaborative performance of the internal network, and in particular the jobrotation between business functions. It gives the organization a greater knowledge about internal functions and creates connections between departments. Even though many of the informants have had jobs in other business functions, they still considered it to be a rare thing to change jobs between business functions at the company; a more typical career path is within a business function.

\section{MEASURING INNOVATION CAPABILITY}

As noted earlier, the aerospace industry is characterized by long lead times and product lifecycles in, and considering that it takes years, even decades, for an idea to fully realize its potential and become an innovation on the market, it is very difficult for a company in such an industry context to know already in the early stages that they are on the path to innovation. Knowing how innovative they are long before the product has reached the market implies a need to measure the innovation capability related to 'work in progress'.

The majority of informants were positive to the idea of measuring the innovation capability at the company. One person was a bit hesitant regarding the use of the outcome of the measure and considered the involvement in the engine programs and the technology development for example to be 'proof' enough that they are innovative; otherwise the OEM would not choose them as partners. There were also expressed needs for 'simple' metrics, that changes could be observed in a fairly short period of time and that one would see the immediate effect of one's own work. There was also an expressed need to highlight the good examples of company innovations, those products that were developed twenty years ago and are still on the market.

The metrics that are used today in order to measure innovation capability at the company are (1) customer satisfaction, (2) brand platform, (3) return on investment, (4) number of patents, and (5) number of patent applications. The area of patents is not discussed in this paper since it is not directly linked to collaboration and network innovation. The collaboration with the customer will of course affect both the customer satisfaction and the brand platform, but these metrics do not give the complete picture of the collaborative innovation capability.

All different types of collaboration need to be measured to give a justified result of the company. In previous sections of this paper, seven types of collaboration have been identified from the point of view of the cross-functional project team (See Figure 1, below):

1. Collaboration within the department: individuals within a team collaborate with colleagues who are found within their department, but who are not part of the team.

2. Collaboration within the business function: individuals within a team collaborate with colleagues who are found within their business function, but who are not part of the team. 
3. Collaboration within the company: individuals within a team collaborate with colleagues from different business functions.

4. Collaboration within the Group: individuals within the company collaborate with individuals in other companies within the Group.

5. Collaboration with 3rd parties such as universities: the team collaborates externally with e.g. universities.

6. Collaboration with suppliers: the team collaborates externally with suppliers and potential future suppliers.

7. Collaboration with customers/partners: the team collaborates with customers/partners or potential future customer/partners.

8. Collaboration with customers of the customer: the team collaborates with the customers' customer, e.g. aircraft manufacturers and airlines.

The suggested metrics in this paper are divided into 'Activity' and 'Effect' so that the focus is not only the outcome, but also on the ways of working in the organization and the activities that are performed (see Table 1, below).

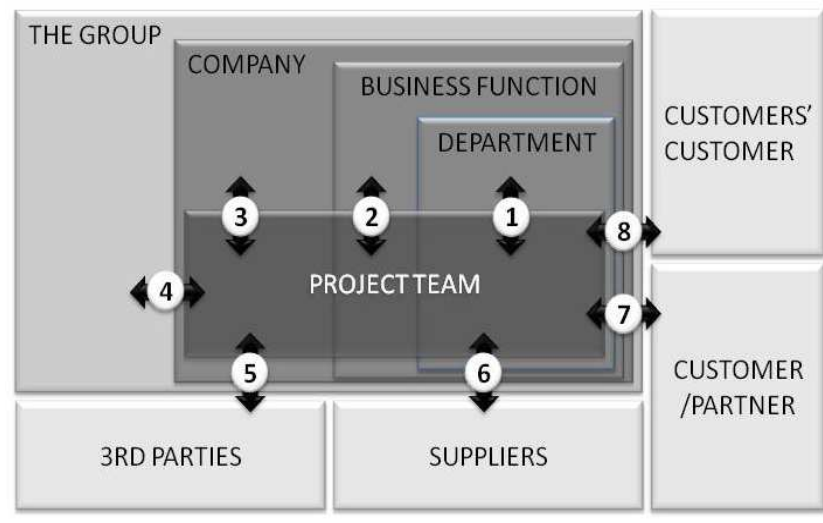

Figure 1: Different types of internal and external collaboration

Both quantitative and qualitative metrics are used in order to capture the full range of the innovative process. Each activity metric needs to be measured for each of the eight types of collaboration that were identified at the company.

\begin{tabular}{|l|l|l|l|}
\hline ACTIVITY & Description / Examples & EFFECT & Description / Examples \\
\hline $\begin{array}{l}\text { Quantity of collaboration } \\
\text { activities/connections }\end{array}$ & $\begin{array}{l}\text { External: number of customers' } \\
\text { customer meetings, number of } \\
\text { customer/partner meetings, number } \\
\text { of supplier meetings, number of } 3^{\text {rd }} \\
\text { party meetings } \\
\text { Internal: number of cross-boundary } \\
\text { (team, department, function, } \\
\text { company) meetings }\end{array}$ & $\begin{array}{l}\text { Customer satisfaction } \\
\text { Index establishes whether or } \\
\text { not customers are satisfied } \\
\text { with the PSS solution. }\end{array}$ \\
\hline $\begin{array}{l}\text { Quality of collaboration } \\
\text { activities/connections }\end{array}$ & $\begin{array}{l}\text { Did the meeting involve collaborative } \\
\text { ideation or only exchange of } \\
\text { information? }\end{array}$ & $\begin{array}{l}\text { Return on Investment } \\
\text { (ROI) on innovation } \\
\text { projects }\end{array}$ & $\begin{array}{l}\text { Is the company earning } \\
\text { money on their PSS } \\
\text { solutions? }\end{array}$ \\
\hline $\begin{array}{l}\text { Subjective assessment of } \\
\text { project handovers }\end{array}$ & $\begin{array}{l}\text { What word would summarize the } \\
\text { handover? (e.g. stressful, smooth, })\end{array}$ & $\begin{array}{l}\text { Project/products } \\
\text { delivering on time }\end{array}$ & $\begin{array}{l}\text { Number of delayed delivery } \\
\text { days }\end{array}$ \\
\hline $\begin{array}{l}\text { Subjective assessment of the } \\
\text { communication activities }\end{array}$ & $\begin{array}{l}\text { Availability of tools for } \\
\text { communication activities, for both } \\
\text { direct and indirect communication }\end{array}$ & Product quality & Requirement fulfillment \\
\hline $\begin{array}{l}\text { Satisfaction of methodology } \\
\text { for collaboration activities }\end{array}$ & $\begin{array}{l}\text { Subjective assessment of the } \\
\text { methodology used for collaboration }\end{array}$ & Large amount of ideas & $\begin{array}{l}\text { Number of ideas from } \\
\text { different sources, number of } \\
\text { ideas in total, number of } \\
\text { ideas lead to concluded } \\
\text { business }\end{array}$ \\
\hline
\end{tabular}

Table 1: Metric divided into Activity and Effect.

\section{CONCLUSIONS}

In this paper eight different types of collaborations (both internal and external) are identified and a set of metrics, divided into 'Activity' and 'Effect', are proposed. The set of metrics was based on the findings through interviews and literature, collectively supporting that innovation for product service systems is linked to collaborative performance.

Since the company has a strong division through in service business, and another in hardware focused business on the commercial engines side, collaboration within the company as well as with new types of external partners needs development to become product service providers. Also, within already established collaborations, the role and type of collaboration need to be improved. It is evident from the military side that the unique and tight connection to the customer is one success factor to that service integration in product offers is more mature. It is recognized that the aerospace business has long product lifecycles, which is likely to impact the rate of change in new innovation schemes.
Regarding activity metrics, the pure number of collaborative activities aims to measure the degree of collaboration, where more activities would indicate a more active collaborative work. It is important to recognize that not only established partner collaboration is measured, but also collaboration with partners contributing to future PSS solutions, such as universities, new type or suppliers and customers. A qualitative measure to explore the degree of ideation in the collaboration activities is proposed in combination. Activity measures to evolve the internal collaborative performance include measuring the quality of responsibility handover through the lifecycle, the use of available tools for collaboration and the perceived satisfaction during internal collaboration.

It is expected that effect measures will show change over longer time. Most important is to include the PSS aspect into the customer satisfaction measures already conducted. Quantitative effect measures include pure counting of ideas, business proposals and concluded new businesses. 
Some conditions found that need to be considered in developing new type of innovative capabilities are:

- Customer relation with manufacturing OEM's need to evolve, since services are consumed by airlines

- $\quad$ Aerospace regulation and long life-cycle of products and business contracts may act as conservation mechanism when introducing new innovation models.

- $\quad$ Long term customer relation is significant for building trust and reducing risk in new innovations with service content.

- The company in the study has opportunities to use capabilities within the Group, where complementary skills exist

- True exploitation of internal and external capabilities to combine service expertise and hardware expertise require senior level ambitions and directives since the established way of working not naturally has this focus.

- Common business focus within different functions supports internal collaboration

- Innovations including services for product development should be included in advance of contractual development.

Changing to a service-focused mindset in the organization could mean a need for shorter decision processes. It would also include increased internal collaboration. However, a systematic decision process is already in place at the company, serving to evaluate the decisions whether or not to join the large engine programs.

The internal collaboration is easier when the individuals have the same business perspective, i.e. belong to the same business function within the organization. Job rotation can provide a new perspective; it gives the organization a greater knowledge about internal functions and creates connections between departments.

Measuring innovation may be one of the useful useful tools in this process as it would provide useful insights and facts on how innovative the company is long before the product or service has reached the market.

\section{ACKNOWLEDGEMENTS}

Financial support from Vinnova through PIEp, and Volvo is greatly acknowledged. The authors are also grateful for the time and participation from interviewees and colleagues.

\section{REFERENCES}

[1] Baines, T. S.; Lightfoot, H. W.; Evans, S.; Neely, A.; Greenough, R.; Jeppard, J.; Roy, R., Shehab, E.; Braganza, A.; Tiwari, A.; Alcock, J. R.; Angus, J. P.; Bastl, M.; Cousens, A.; Irving, P.; Johnson, M.; Kingston, J.; Lockett, H.; Martinez, V.; Michele, P.; Transfield, D.; Walton, I. M.; Wilson, H. (2007): State-of-the-art in productservice systems, J. Engineering Manufacture, Vol. 221 Part B

[2] Wallin, J.; Isaksson, O.; Larsson, A.; Larsson, T. (2010): Measuring Innovation Capability in Technology-Focused Development, 17th International Product Development Management Conference, Murcia, Spain, June 13-15.

[3] Olsson, A. (Ed.) (2008): PIEp, Product Innovation Engineering Program, Innovationsförmåga. ISBN: 978-91977852-0-4.

[4] Schramm, C. (Ed.) (2008): Innovation Measurement Tracking the State of Innovation in the American Economy, A report to the Secretary of Commerce by The Advisory
Committee on Measuring Innovation in the 21st Century Economy.

[5] Andrew, J.; Sirkin, H.; Haanaes, K.; Michael, D. (2007) Measuring Innovation 2007, A BCG Senior Management Survey, The Boston Consulting Group.

[6] Chiesa, V.; Frattini, F.; Lazzarotti, V.; Manzini, R. (2009): Performance measurement in R\&D: Exploring the Interplay between Measurement Objectives, Dimensions of Performance and Contextual Factors. R\&D Management, Vol. 39, Issue 5, pp. 487-519.

[7] Cordero, R. (1990): The measurement of innovation performance in the firm: an overview, Research Policy, Vol. 19, pp.185-192.

[8] Rosenzweig, P. (2007): Misunderstanding the nature of company performance: the halo effect and other business delusions, California Management Review, Vol. 49, No.4, pp. 6-20.

[9] Muller, A.; Valikangas, L.; Merlyn, P. (2005): Metrics for innovation: guidelines for developing a customized suite of innovation metrics, Strategy \& Leadership. 33(1) pp. $37-45$.

[10] Werner, B.; Souder, W. (1997): Measuring R\&D Performance - State of the Art, Research Technology Management: ProQuest Science Journal: Mar/Apr, Vol. 40, No. 2; pp. 34-42.

[11] Chan, V.; Musso, C.; Shankar, V. (2008): McKinsey Global Survey Results: Assessing innovation metrics, The McKinsey Quarterly.

[12] Harrison, A. (2006): Design for service - Harmonising product design with a services strategy, Proceedings of the ASME Turbo Expo 2006, Vol 2, Barcelona, Spain, May 06-11.

[13] Beauvilliard, A.; Jentzsch, A.; Kurmann, D.; Obring, K.; Ulrich, P. (2009): Achieving Excellence in After-Sales Services - A Primer for Industrial Companies, The Boston Consulting Group. September.

[14] Schaper, M. (2010): Tackling IT complexity in product design, McKinsey Quarterly, McKinsey \& Company.

[15] Sivathanu Pillai, A.; Joshi, A.; Srinivasa Rao, K. (2002): Performance measurement of R\&D projects in a multi-project, concurrent engineering environment, International Journal of Project Management 20, pp. 165-177.

[16] Cao, M.; Zhang, Q. (2010): Supply chain collaborative advantage: A firm's perspective, Int. J. Production Economics 128, pp. 358-367.

[17] Eppinger, S.; Chitkara, A. (2006): The New Practice of Global Product Development, MIT Sloan Management Review. Summer 2006, Vol. 47 No.4, pp. 22-30.

[18] Brown, T. (2008): Design Thinking, Harvard Business Review. June 2008, pp. 84-92.

[19] Björklund, T. (2010): Enhancing creative knowledge-work: challenges and point of leverage, International Journal of Managing Projects in Business, Vol.3 No.3, pp. 517-525.

[20] Amabile, T. (1998): How to Kill Creativity, Harvard Business Review. September-October 1998, pp. 77-87.

[21] Sosa, M.; Eppinger, S.; Rowles, C. (2007): Are Your Engineers Talking to One Another When They Should?, Harvard Business Review. November 2007, pp. 133-142. 